\title{
UMA INVESTIGAÇÁO DA INFLUÊNCIA DE DISPOSITIVOS DA ENGENHARIA DE TRÁFEGO NO SISTEMA VIÁRIO: INTERVENÇÃO NA RUA PADRE AGOSTINHO
}

\author{
M. A. P. Bernardinis ${ }^{1}$; L. M. Pavelski²; A. T. G. Molinari³; B. M. C. B. Kureke ${ }^{4}$ \\ 1,2,3.4 Universidade Federal do Paraná, Rua Francisco H. dos Santos, s/n. \\ profmarcia.map@gmail.com¹,luziane_machado@hotmail.com², alanamolinari22@gmail.com³, \\ brunabuher@gmail.com ${ }^{4}$
}

\begin{abstract}
Resumo: $\mathrm{O}$ presente trabalho trata de uma investigação da influência de dispositivo da engenharia de tráfego no sistema viário, por intermédio de um estudo de caso da Rua Padre Agostinho, na cidade de Curitiba, do estado do Paraná (Brasil). O dispositivo em questão se refere à transformaçáo de vagas de estacionamento, presentes na via, em uma faixa adicional de tráfego. O principal objetivo dessa intervenção é aumentar a fluidez do tráfego de veículos no local. Para tanto, foram realizadas pesquisas com moradores, comerciantes e um motorista de transporte coletivo da regiáo, para conhecimento da opiniáo quanto ao dispositivo implantado. Além disso, foi realizada uma pesquisa de campo para a obtenção de informaçóes sobre o local, a velocidade, o fluxo e o volume de veículos referente ao trecho estudado. Este trecho é de elevada importância para a cidade, pois trata-se de um grande corredor viário, utilizado para ligar o centro ao noroeste da cidade. Através dos estudos realizados constatou-se que as características da via não condizem com as recomendaçóes existentes. Os resultados mostram que a utilização de faixas com medidas abaixo do recomendado interfere no trânsito, causando diminuição de velocidade e de volume tráfego na via. Além dos problemas visualmente perceptíveis, existe também o desconforto do usuário ao utilizar uma via com essas novas características.
\end{abstract}

Palavras-chave: Engenharia de tráfego, Estacionamento, Largura de faixa, Velocidade, Conforto do usuário.

\begin{abstract}
The present paper deals with an investigation of the influence of traffic engineering in the road system, through a case study of Rua Padre Agostinho, in the city of Curitiba, in the state of Paraná (Brazil). The device in question refers to the conversion of parking spaces, present on the road, into an additional band of traffic. The main purpose of this intervention is to increase the flow of on-site vehicle traffic. For that, research was conducted with residents, merchants and a collective transportation driver of the region, to know the opinion about the implanted device. In addition, a field survey was carried out to obtain information on the location, speed, flow and volume of vehicles related to the studied section. This stretch is of great importance to the city, as it is a great road corridor, used to connect the center to the northwest of the city. Through the studies carried out it was verified that the characteristics of the track do not comply with the existing recommendations. In addition, the results show that the use of banners with measures below the recommended one interferes in the traffic, causing decrease of speed and of volume traffic in the way. In addition to the visually noticeable problems, there is also user discomfort when using a route with these new features.
\end{abstract}

Keywords: Traffic engineering, Parking, Bandwidth, Speed, User comfort. 


\section{Introduçáo}

A verticalização de áreas centrais e o crescimento do número de veículos aumenta consideravelmente a demanda por espaço viário nos grandes centros urbanos. Nesse sentido, um dos grandes desafios da atualidade, com que se deparam os responsáveis pelo planejamento das cidades, é o de melhorar a qualidade de vida nesses locais e atender à exigência gerada pela demanda da população, quanto às suas necessidades de circulação dentro do perímetro urbano. Para isso, é necessário que haja intervençôes no sistema de trânsito, de modo a facilitar a circulação, minimizando os efeitos do uso massivo de veículos. Assim sendo é preciso buscar soluçôes, preferencialmente inovadoras e amparadas por tecnologias atuais, para a realização dessa melhoria.

Desse modo, existem diversos dispositivos de Engenharia de Tráfego que atuam na melhoria do sistema viário. Um desses dispositivos, que se observa com bastante frequência nas grandes cidades, é a retirada de estacionamento para aumentar a capacidade da via. Embora não seja, nesse tempo, uma ideia inovadora, apresenta características notoriamente importantes na melhoria da fluidez do trânsito.

Alguns desses dispositivos, utilizados como solução, deixam margens de dúvidas quanto à sua eficiência. Com a elaboração desse trabalho pretende-se, por intermédio de um estudo de caso, verificar o impacto gerado na substituição de uma faixa de estacionamento por uma faixa de tráfego de veículos e analisar o fluxo de veículos quanto à velocidade média de tráfego com relação à largura das faixas. O referido estudo se deu na Rua Padre Agostinho, grande corredor viário, utilizado para ligar o centro ao noroeste da cidade de Curitiba, no trecho entre as Ruas Alameda Presidente Taunay e Fernando Simas. Neste trabalho a Rua Padre Agostinho foi escolhida, por já existirem estudos de tráfego nesta, anteriores à retirada da faixa exclusiva para estacionamento, possibilitando a realizaçáo de um estudo de forma mais assertiva, com resultados mais próximos à realidade.

\subsection{Mobilidade urbana nas grandes cidades}

A mobilidade urbana e suas implicações têm se configurado como um dos maiores desafios deste século para a sustentabilidade nas cidades. O termo "mobilidade urbana" surgiu a partir da conciliação de alguns fatores: crescimento da cidade, geração de renda, emprego e renovação das estruturas de transporte [5]. A capacidade das principais cidades do mundo de absorver mais carros há muito tempo dá sinais de esgotamento.

No período de 2002 a 2012, a frota de veículos no Brasil teve um aumento significativo de $400 \%$. Esse quadro tem exigido uma nova postura por parte das prefeituras e da sociedade para a busca de soluçôes [5]. A seguir, na Tabela 1, seguem alguns dados referentes a algumas capitais do Brasil. 
Tabela 1 - Dados de mobilidade de algumas capitais do Brasil.

\begin{tabular}{ccccc}
\hline & Porto Alegre & Rio de Janeiro & Curitiba & Sáo Paulo \\
\hline População & 1.416 .714 & 6.390 .290 & 1.776 .761 & 11.376 .685 \\
Frota de Veículos & 786.235 & 2.397 .904 & 1.404 .235 & 6.924 .394 \\
Veículos por pessoa & 0,6 & 0,4 & 0,8 & 0,6 \\
\hline
\end{tabular}

Para a cidade de Curitiba, pode-se ver claramente a partir dos dados citados anteriormente que a relação veículo/pessoa tem um valor de 0,8 , ou seja, quase um veículo por habitante. É consenso que o efeito negativo de congestionamentos e poluição em Curitiba e outras cidades se devem principalmente ao uso do veículo individual. Os fatores negativos atrelados ao uso do automóvel são embasados por números da Associação Nacional de Transporte Público. Enquanto no ano de 2012 os transportes coletivos consumiram 25\% da energia gasta no transporte urbano, automóveis e motocicletas consumiram 75\%, e responderam por menos da metade dos deslocamentos [1]. Entretanto, existem diversos dispositivos de Engenharia de Tráfego que atuam na melhoria do sistema viário. Um desses dispositivos, que vem ocorrendo com bastante frequência nas grandes cidades é a retirada do estacionamento para aumentar a capacidade da via.

\subsection{Fatores que afetam a capacidade e os volumes de serviço}

Alguns fatores podem interferir nas condiçôes naturais de capacidade e volume de serviço e podem ser divididos em categorias. $\mathrm{O}$ que diz respeito à largura da faixa tem especial relevância, pois é bastante pertinente ao estudo de caso desta comunicação técnica.

Segundo [4], as faixas mais estreitas têm menor capacidade sob condiçóes de fluxos contínuos do que as faixas de $3,60 \mathrm{~m}$, aceitas como limite, acima do qual a capacidade da via não sofre mais acréscimo. Numa via de duas faixas e mão dupla, um veículo, para efetuar ultrapassagem, obstrui a faixa de sentido contrário ao seu por um tempo maior quando as faixas são mais estreitas. Em vias de várias faixas os veículos invadem as faixas adjacentes com maior frequência quando elas são mais estreitas, ocupando duas faixas em vez de uma.

Ainda segundo o mesmo autor, os valores de referência adotados para a capacidade de uma via semaforizada incluindo vários fatores como espaçamento entre os veículos e poder de frenagem é de 1800 veíc/h, por faixa, de 3,5m de largura, plana, bem pavimentada, com tempo bom. Açóes como redução na largura de faixas pode ocasionar interferência na capacidade de uma via. Por exemplo, reduzindo-se de $3,5 \mathrm{~m}$ para $2,5 \mathrm{~m}$, poderá haver o acréscimo de uma faixa. De acordo com [4], a providência de se reduzir a largura das faixas deve ser reservada para casos críticos de falta de capacidade, pois traz desconforto aos motoristas. 


\subsection{Legislaçóes com relação às dimensóes de faixas de tráfego}

É de responsabilidade da União, dos estados e dos municípios a regulamentação de largura mínima para faixas de tráfego. Apesar disso não existe uma lei que forneça obrigatoriedade da largura das faixas. $\mathrm{O}$ [2] determina que a resoluçáo no 236 forneça validade legal ao capitulo de sinalizaçáo horizontal do manual brasileiro de trânsito, que determina 2,5 metros a largura mínima para uma faixa, porém no texto este dado aparece apenas como uma recomendação, o que cria margem de dúvidas quanto à interpretação e não torna a resolução obrigatória.

\section{Metodologia}

A área de estudo se localiza na Rua Padre Agostinho, no trecho entre as Ruas Presidente Taunay e Fernando Simas. Trata-se de uma via de fluxo intenso, com grande circulação de ônibus de transporte público - mini ônibus e ônibus convencional -, que liga o centro a um bairro extremo da cidade. Quando havia a faixa exclusiva para estacionamento, ela possuía 2,28m de largura. A via possui atualmente quatro faixas de tráfego, com largura média de $2,33 \mathrm{~m}$, que vão em direção ao Bairro. Em 2002 foi realizada uma pesquisa de contagem de tráfego. Em 2006 a mesma pesquisa foi realizada pelo Diretran (atual Setran). Essas pesquisas foram utilizadas como base de dados para o estudo em questão.

\subsection{Caracterizaçáo da via no ano de 2008}

Em 2008 houve a mudança das faixas de rolamento da Rua Padre Agostinho, a faixa específica para estacionamento foi modificada tornando-se uma faixa adicional de tráfego. A largura atual das faixas são de 2,34m, 2,25m, 2,43m e 2,31m. Também houve a instalação de um semáforo na interseção com a Rua Alameda Presidente Taunay.

\subsection{Levantamento de dados}

Foram coletados em campo todos os dados necessários para a realização da pesquisa como:

- Pesquisa de Contagem Volumétrica $(2 \mathrm{~h})$ - foi realizada no mesmo dia e horário das pesquisas anteriores, em uma terça feira das $17 \mathrm{~h}$ às $19 \mathrm{~h}$ (período de duas horas), a fim de incluir dados ao trabalho, e fazer comparação entre as contagens de 2002 e 2006 realizadas pelo Instituto Bonilha e pelo Diretran.

- Pesquisa de Contagem Volumétrica (15min) - a fim de conhecer a atual realidade do volume de veículos que trafegam diariamente na Rua Padre Agostinho, foi realizada uma 
pesquisa em uma terça feira às $17 \mathrm{~h}$ e $40 \mathrm{~min}$ por um período de 15 minutos na Rua Padre Agostinho com as ruas Alameda Presidente Taunay e Fernando Simas.

- Pesquisa de velocidade média de tráfego - Velocidade média que o veículo leva para percorrer um trecho em um determinado tempo. Os trechos percorridos foram os seguintes: Rua Padre Agostinho e Rua Martim Afonso, entre as ruas Alameda Presidente Taunay e Fernando Simas. A Rua Martim Afonso também foi pesquisada para tornar possível a comparação com as velocidades obtidas na Rua Padre Agostinho.

- Entrevistas - Foram realizadas seis entrevistas com moradores da região, nove comerciantes e um motorista de ônibus (transporte público), a fim de se obter dados da via, e fazer a comparação do antes depois da retirada das vagas de estacionamento. As perguntas eram diferentes em quantidade e conteúdo conforme o tipo do entrevistado, porém todas basicamente possuíam o intuito de captar a percepção dessas pessoas sobre acidentes, sinalização e mudanças observadas.

\section{Resultados}

Como já mostrado no item 2, a contagem volumétrica do ano de 2002, Instituto Bonilha, resultou um valor de UCP igual a 1994 veículos/hora. Em 2006, Diretran, a contagem resultou em um valor igual a 3030 veículos/hora. A última pesquisa, realizada pelas autoras do trabalho, resultou em um valor UCP igual a 3654 veículos/hora. Através dos resultados mencionados acima, pode-se perceber um aumento de 45,4\% de veículos que passam no trecho em estudo, entre os anos de 2002 e 2013, o que é muito significativo.

Quanto aos resultados de velocidade média, obteve-se para a Rua Padre Agostinho $57 \mathrm{~km} / \mathrm{h}$, velocidade essa inferior a desejável de $60 \mathrm{~km} / \mathrm{h}$. Já na Rua Martim Afonso, a velocidade média dos veículos resultou em $72 \mathrm{~km} /$ hora, o que significa que os veículos trafegam com $20 \%$ a mais de velocidade se comparado com a Rua Padre Agostinho, que possui o mesmo número de faixas, entretanto mais estreitas. Com as mediçóes e o paralelo comparativo realizado com a rua Martim Afonso contatou-se que apesar da açáo de retirada de uma faixa de estacionamento a favor de um número maior de faixas de tráfego ser uma medida adotada em função de melhorar o fluxo de veículos o resultado foi diferente do esperado, pois a largura fora dos padróes mínimos recomendados gerou nos motoristas receio a ponto de diminuir a velocidade por segurança.

Já com relação às entrevistas feitas, o que mais se destacou foi o questionamento sobre as mudanças percebidas na via depois da inclusão da nova faixa: diminuição da velocidade do tráfego, aumento do número de veículos, diminuição do conforto e dificuldade para estacionar. Dentre esses aspectos o que teve maior impacto foi a dificuldade para estacionar citada por $50 \%$ dos entrevistados. $42 \%$ dos entrevistados consideraram a mudança ruim e também foi citado o desconforto causado pela pouca distância entre as faixas. Destacou-se também a dificuldade diária do motorista de ônibus 
em realizar uma direção defensiva sendo a via tão estreita, a situação também foi apontada por comerciantes e moradores como causa de pequenos acidentes.

\section{Conclusóes}

Pode-se verificar com este trabalho que os problemas de mobilidade ocorrem em todo o mundo. Cada região possui características que proporcionam soluçóes que lhe cabem melhor, assim, todo estudo referente ao tráfego deve ser afunilado de tal forma que tragam os resultados mais favoráveis possíveis para o local.

Os resultados comprovaram que a intervenção na via não trouxe o resultado satisfatório, apesar de acrescentar uma faixa, a via não tem a mesma eficiência que a Rua Martim Afonso, que possui características semelhantes, mas com a diferença de possuir faixas mais largas. Através dos estudos chegou-se a conclusão de que a Rua Padre Agostinho deveria ser redimensionada. Ao invés de ter quatro faixas, o melhor seria ter três faixas com aproximadamente $3 \mathrm{~m}$ de largura cada, trazendo mais conforto aos motoristas, comportando os veículos de maior porte adequadamente e com aumento na velocidade média.

Outras alternativas, mas que requerem estudos específicos seriam:

- Redimensionar as quatro faixas já existentes, avançando sobre o perímetro dos passeios;

- Criar uma faixa mais larga e exclusiva para os veículos de maior porte;

- Incentivos econômicos e facilidades de crédito para a população para a compra de veículos de menor porte.

É preciso levar em consideração que as mudanças no tráfego são constantes, portanto não é recomendado se ater apenas a implantação de uma medida para melhoria sem as pesquisas e soluçóes da Engenharia de Tráfego. O desenvolvimento urbano em determinadas regiôes, portanto, pode tornar ineficientes as técnicas de intervenção utilizadas anteriormente, sendo necessário adaptá-las visando um resultado compatível com as necessidades locais.

\section{Referências}

[1] ANTP (2012). Associaçáo Nacional de Transporte Público. Disponível em: <http://www.antp.org.br/>. Acesso em: 10 nov. 2017.

[2] CONTRAN (2007) Manual Brasileiro de Sinalização - Volume IV- Sinalização horizontal, cap 5. Resoluçáo $236 / 07$.

[3] MOBILIZE. Dados de mobilidade. Disponível em: <http://www.mobilize.org.br/acompanhe-a-mobilidade/ default.aspx? cidade=4>. Acesso em: 12 nov. 2017. 
[4] NETO, J. C.; Notas De Aula (1 e 5). Disponível em: <http://meusite.mackenzie.com.br/professor_cucci/aulas. htm>. Acesso em: 2 nov. 2017.

[5] REBOUÇAS, F.; Mobilidade urbana. Disponível em: <http://www.infoescola.com/transporte/mobilidadeurbana/>. Acesso em: 4 nov. 2017. 